\title{
BERYLLIUM DRIVEN HEMATOLOGICAL AND SEROLOGICAL ALTERATION; THAT CURED BY CHELATION VIA NARINGENIN IN ALBINO RATS
}

\author{
ANJANI VERMA ${ }^{1}$, SAMRAT RAKSHIT ${ }^{1}$, SATYENDRA KUMAR NIRALA ${ }^{2}$, MONIKA BHADAURIA $^{1 *}$ \\ ${ }^{1}$ Toxicology and Pharmacology Laboratory, Guru Ghasidas Vishwavidyalaya, Bilaspur, Chhattisgarh, India. ${ }^{2}$ Department of Rural Technology \\ and Social Development, Laboratory of Natural Product, Bilaspur, Chhattisgarh, India. Email: bhadauria_monika@rediffmail.com
}

Received: 10 June 2019, Revised and Accepted: 09 July 2019

\section{ABSTRACT}

Objective: Environment faces range of pollutions threats due to extensive industrialization and deforestation. In exists scenario metal contamination deadly one among them. Beryllium is $44^{\text {th }}$ most abundant element in earth crust which executes their discharge in society through fossils fuel combustion besides daily routines things as in chips of electric gadgets jewelry, dental crown. The objective of the present investigation was the reduction of beryllium harmful effect through naringenin in female albino rats.

Methods: Female rats were administered by $1 \mathrm{mg} / \mathrm{kg}$ dose intraperitoneally daily for 28 days alone as well as before/along with three doses (12.5, 25, and $50 \mathrm{mg} / \mathrm{kg}$ ) of naringenin orally (7 days once in day). Hematological and serological analysis was performed for this clinical research.

Results: Beryllium exposure caused severe alteration in hematological markers evident by a significant diminishment of hemoglobin, red blood corpuscles, mean corpuscular hemoglobin concentration and hematocrit and promoted the level of white blood corpuscles and platelets. Similarly, serological parameters; triglycerides cholesterol and glucose were altered significantly as the response of lipid bilayer peroxidation. All these variables were retrieval near to control ardently by three doses of naringenin.

Conclusion: In short naringenin might be useful as in natural chelation for beryllium body burden.

Keywords: Beryllium, Naringenin, Hemoglobin, Triglyceride, Glucose.

(c) 2019 The Authors. Published by Innovare Academic Sciences Pvt Ltd. This is an open access article under the CC BY license (http://creativecommons. org/licenses/by/4. 0/) DOI: http://dx.doi.org/10.22159/ajpcr.2019.v12i9.34517

\section{INTRODUCTION}

Metal contamination and its health hazards have pose great threat to the general population at costs of deforestation, heavy industrialization, and reconstruction of the world [1]. India has also step-up in these circumstances since past decay by reason of industrial competition over other countries. Numerous metal pollution and their toxic manifestations cases have been well studied previously. Beryllium is one of the alkaline earth metals among 23 elements are comprised in pollutant's list as per the ATSDR (Agency for Toxic Substances and Disease Registry) toxicological report 2018 [2]. In this queue beryllium is one of the light metal that possess unique features makes it reliable to various applications (aerospace, electronic gadgets, heat insulators, non-sparkling tool etc.) $[3,4]$. Due to their wide-range of regular uses; its exposure and emission become more usual. Fossils fuel combustions a chief source of its emission [5,6]. Several coal mines in India have the main root for electricity and energy generation. However, their ashes have metal particles polluted the near area of a power plant in industries.

During past decay plant containing natural products like polyphenol flavonoids got more attention by scientific communities [7]. Several ailments including diabetes, hypertension, and carcinoma were cured by natural products and their derivative compounds [8,9]. Diet based biomolecules such as flavonoids have therapeutic potential and are thought to be a suitable agent in the prevention and improvement of various diseases [10]. Naringenin (4',5,7-thrihydroxyflavanone) is a predominant bitter and colorless fl. Narin that occurs naturally in vegetables, fruits, herbs, and nuts widely consumed by humans including Lycopersicum esculentum (tomato) [11], Citrus paradise (grapefruit) [12], and Citrus sinensis (orange) [8,13,14].

An increasing number of pre-clinical studies suggest that naringenin offerings wide range of pharmacological effects, including antioxidant [15], anti-inflammatory [16], antidiabetic [17], antimutagenic effects [18,19], and modulation of hepatic apolipoprotein and lipid synthesis. Previous literature was revealed that naringenin inhibits heavy metal-induced toxicity [20]; however, there is no evidence on the mechanism of preventive action of naringenin against beryllium (a light metal) induced toxic manifestations in albino rats. This preclinical trial, we demonstrate that beryllium caused an impediment in serum and blood cell's functions, through the therapeutic potential of naringenin.

\section{METHODS}

\section{Animals}

Female albino rat sensitive toward beryllium intoxication (Wistar strain) so on that purpose taken female albino rats for this investigation. About $160 \pm 10$ g weighted albino rats were purchased from Defense Research and Development Establishment, Gwalior, Madhya Pradesh, India. They were kept standard husbandry situations of light $(14 \mathrm{~h})$ and dark $(10 \mathrm{~h})$ at $25 \pm 2^{\circ} \mathrm{C}$ temperature and relative humidity of $65-70 \%$. The rats were fed on a standard pelleted diet (Pranav Agro Limited, Pune) and water ad libitum. Animals were cared in accordance with the guidelines recommended by the committee for the purpose of control and supervision of experiments on animals (994/Ere/GO/06/CPCSEA).

\section{Chemicals and reagents}

Naringenin was procured from Sigma-Aldrich Co. PVT. Limited. Diagnostic kits were purchased from EBRA, Mannheim GmbH Mallaustr, Germany and Meril, India.

\section{Toxicant}

Beryllium was obtained from Dr. S. K. Nirala as a gift which utilized for induction of hepatorenal intoxication. Beryllium nitrate was administrated $1 \mathrm{mg} / \mathrm{kg}$ dose intraperitoneally daily and once for 4 weeks as per [21,22]. 
Therapeutic agent

Naringenin was used as a therapeutic agent at three successive doses $12.5 \mathrm{mg} / \mathrm{kg}, 25 \mathrm{mg} / \mathrm{kg}$, and $50 \mathrm{mg} / \mathrm{kg}$, p.o. for past 7 days after and along with beryllium administration.

\section{Study design}

In this experiment, animals were divided into six groups of six animals in each as follows. Beryllium was administered intraperitoneally for 4 weeks once/day. Naringenin served as, at 12.525 and $50 \mathrm{mg} / \mathrm{kg}$ dose were given last week after and along with beryllium exposure.

\section{Serological assessment}

Animal was euthanized and sacrificed after $24 \mathrm{~h}$ of the last dose. Blood is drawn by puncturing retro-orbital sinus and collected to ethylenediaminetetraacetic acid (EDTA) vials as well as centrifuged tubes for separation of serum.

\section{Hematological assessment}

For hematological studies, blood sample was collected in EDTA tube to maintain their liquidity then assisted through "HEMA2062+" blood analyzer. The serological biochemical assessment was done through serum separation and their analysis by the kit method. For that, blood samples were allowed to stand at room temperature for $1 \mathrm{~h}$ then centrifuged at $3000 \mathrm{rpm}$ for $10 \mathrm{~min}$ to obtain serum that was stored at $-20^{\circ} \mathrm{C}$. Serum was used for the analysis of triglycerides, cholesterol, and glucose using diagnostic kits (Erba Diagnostics, Germany) according to the manufacturer's instructions.

\section{Statistical analysis}

Statistical data were expressed as mean \pm standard error of six animals used in each group. Significance of differences between mean values was determined by one-way analysis of variance (ANOVA) at ${ }^{\ddagger} \mathrm{p} \leq 0.05$ followed by Student's t-test at ${ }^{\Psi \Psi} \mathrm{p} \leq 0.01$ and ${ }^{\Psi} \mathrm{p} \leq 0.05$ for comparison between experimental control and control group whereas a significant difference among therapeutic group versus experimental control group was marked as ${ }^{\Phi \Phi} \mathrm{p} \leq 0.01$ and ${ }^{\Phi} \mathrm{p} \leq 0.05$ [23].

\section{RESULTS AND DISCUSSION}

In the present scenario, naturally occurring bioactive compounds utilized to generate novel antidote or synthetic metal chelators [24]. Natural compounds have rich antioxidant potential with low cost, large quantity available in nature and without involving any toxic sign. Natural products are used as a therapeutic approach for the treatment of numerous disease and abnormalities. Naringenin is a ubiquitous flavanone commonly present in a grapefruit juice at a concentration around $0.05 \mathrm{~g} / \mathrm{L}$ [25] that contributes to several therapeutic actions and chelating effect by due to three hydroxyl groups [26]. Present investigation outcome revealed that administration of beryllium driven severe fluctuations in the hematological parameters that may be caused by mutated hemoglobin molecule. Countless naturally occurring phenolic substances are present in rich amount in the plant kingdom, and their therapeutic potential in reducing toxic metal ion-induced free radical assault is partly attributed to their capability to owe specific chelators which bind to unwanted toxic ions and hence diminish their bioavailability $[27,28]$. In short, these natural products have hydroxyl moieties may assist as substitute remedies or nutritional supplements to mitigate beryllium intoxication. As per chemical name of naringenin indicates 4', 5, 7-trihydroxy flavanone to have "trihydroxy" group in their molecular structure which made it more proficient toward beryllium chelation.

\section{Effect of naringenin on hematological assessments}

Table 1 depicted significantly $(\mathrm{p} \leq 0.01)$ elevated level of platelet and white blood corpuscles after beryllium administration. Their high level might be delivering upgradation of the immune system to compensate for beryllium incited alterations. Although prior research corroboration and support the present outcome [29,30]. Naringenin successive doses also are drawn back altered range of these variables near to control significantly $(\mathrm{p} \leq 0.01)$ by their chelation action on beryllium-exposed rats. In addition hemoglobin, hematocrit (HCT), red blood corpuscles (RBCs), and mean corpuscular hemoglobin concentration (MCHC) were fallen down in beryllium triggered rats as compared to control group significantly $(\mathrm{p} \leq 0.01)$. It may be due to the bone is one of the target sites for beryllium deposition and it also sites of blood synthesis in adults [31]. Beryllium might be intruding the hemopoietin system which can generate blood-related anomalies. Free beryllium can induce alteration of enzyme involved in hemoglobin synthesis which may result immature erythrocytes with reduced oxygen carrying capacity. Reason of deficient hemoglobin might be due to its higher breakdown in comparison with process of its synthesis may become slower-down. Diminished packed cell volume or HCT can occur through following exposure that causes damage to mature erythrocytes or that damages or inhibits replication of erythrocyte progenitors within the bone marrow [32] mean cell hemoglobin concentration (MCHC), HCT, and MCHC that have also been reported in prior literature [21].

In contranst to that hematological markers retrieval toward control by three doses of naringenin significantly $(\mathrm{p} \leq 0.01)$ except hemoglobin. $12.5 \mathrm{mg} / \mathrm{kg}$ dose of naringenin shown significant at $\mathrm{p} \leq 0.05$ (Table 1 ) in the case of hemoglobin. Among all doses of naringenin higher doses, 25 and $50 \mathrm{mg} / \mathrm{kg}$ were showed remarkable recovery as compared to the lowest dose that is also established in previous studies of natural products $[33,34]$.

\section{Effect of naringenin on serological assessment}

Hepatic dysfunction and cell injury tracing a link to beryllium intoxication by an elevated level of serum hepatic biomolecules that leaked out due to damage in the functional integrity of hepatic membrane architecture. Elevation of serum triglycerides and cholesterol on the other hand, blood glucose level were down-regulated by exposure of beryllium which seen in preceding studies [21]. Similarly, outcome observed in the present study where cholesterol and triglyceride levels were upregulated while glucose level was fallen significantly at $\mathrm{p} \leq 0.01$. All doses of naringenin regulated as procured their optimum levels significantly at $\mathrm{p} \leq 0.01$, as shown in Table 2 , that proven by previously published data which is relevant to the present finding $[35,36]$.

Table 1: Influences of naringenin on hematological marker against beryllium-induced toxicity

\begin{tabular}{|c|c|c|c|c|c|c|}
\hline Parameter Unit & Hemoglobin g/dL & $\operatorname{RBCs} 10^{6} / \mathrm{mm}^{3}$ & HCT \% & MCHC g/dL & WBC $10^{6} / \mathrm{mm}^{3}$ & Platelets $10^{3} / \mathrm{mm}^{3}$ \\
\hline Group 1 & $14.1 \pm 0.98$ & $7.33 \pm 0.57$ & $40.9 \pm 2.86$ & $39.5 \pm 2.96$ & $9.71 \pm 0.82$ & $802 \pm 72.9$ \\
\hline Group 2 & $14.2 \pm 1.02$ & $7.31 \pm 0.60$ & $41.3 \pm 3.30$ & $39.2 \pm 3.13$ & $9.51 \pm 0.86$ & $812 \pm 73.1$ \\
\hline Group 3 & $11.8 \pm 0.83^{\Psi \Psi}$ & $3.45 \pm 0.30^{\Psi \Psi}$ & $30.8 \pm 2.27^{\Psi \Psi}$ & $33.1 \pm 2.84^{\Psi \Psi}$ & $19.9 \pm 1.71^{\Psi \Psi}$ & $1226 \pm 84.5^{\Psi \Psi}$ \\
\hline Group 4 & $12.6 \pm 0.63^{\Phi}$ & $5.65 \pm 0.53^{\Phi \Phi}$ & $34.9 \pm 2.89^{\Phi \Phi}$ & $45.5 \pm 3.19^{\Phi \Phi}$ & $12.0 \pm 1.15^{\Phi \Phi}$ & $1036 \pm 96.3^{\Phi \Phi}$ \\
\hline Group 5 & $12.8 \pm 1.02^{\Phi \Phi}$ & $6.04 \pm 0.50^{\Phi \Phi}$ & $35.4 \pm 2.47^{\Phi \Phi}$ & $36.1 \pm 3.42^{\Phi \Phi}$ & $11.9 \pm 0.95^{\Phi \Phi}$ & $950 \pm 81.7^{\Phi \Phi}$ \\
\hline Group 6 & $13.1 \pm 0.92^{\Phi \Phi}$ & $6.71 \pm 0.57^{\Phi \Phi}$ & $36.3 \pm 3.26^{\Phi \Phi}$ & $38.7 \pm 3.52^{\Phi \Phi}$ & $11.7 \pm 0.88^{\Phi \Phi}$ & $915 \pm 84.1^{\Phi \Phi}$ \\
\hline ANOVA & $51.57^{¥}$ & $21.69^{¥}$ & $63.87^{¥}$ & $58.9^{¥}$ & $16.99^{¥}$ & $23.4^{¥}$ \\
\hline
\end{tabular}

Data were expressed as mean \pm standard error of $n=6 ;{ }^{*}$ significant at $0.05 \%$ for ANOVA. ${ }^{\Psi}{ }^{\Psi}$ Beryllium against Control at $\mathrm{p} \leq 0.01$ and ${ }^{\Phi} \mathrm{Be}+\mathrm{Naringenin}$ against Beryllium at $\leq 0.05 ;{ }^{\Phi \Phi} \mathrm{Be}+$ Naringenin against Beryllium at $\mathrm{p} \leq 0.01$ for Student's t-test. RBCs: Red blood corpuscles, MCHC: Mean corpuscular hemoglobin concentration,

HCT: Hematocrit, WBC: White blood corpuscles. Group 1: Control, Group 2: Naringenin per se (Naringenin $50 \mathrm{mg} / \mathrm{kg}$ ), Group 3: Beryllium (1 mg/kg i.p. Once in a day; 4 weeks), Group 4: Beryllium+Naringenin $12.5 \mathrm{mg} / \mathrm{kg}$, Group 5: Beryllium+Naringenin $25 \mathrm{mg} / \mathrm{kg}$, Group 6: Beryllium+Naringenin $50 \mathrm{mg} / \mathrm{kg}$ 
Table 2: Efficacy of naringenin on serological marker against beryllium exposure

\begin{tabular}{llll}
\hline Parameter & Cholesterol & Triglycerides & Glucose \\
\hline Unit & $\mathrm{mg} / \mathrm{dL}$ & $\mathrm{mg} / \mathrm{dL}$ & $\mathrm{mg} / \mathrm{dL}$ \\
Group 1 & $17.2 \pm 0.95$ & $42.1 \pm 2.32$ & $108 \pm 5.97$ \\
Group 2 & $19.1 \pm 1.05$ & $48.4 \pm 2.67$ & $102 \pm 5.63$ \\
Group 3 & $34.3 \pm 1.89^{\Psi \Psi}$ & $97.6 \pm 5.39^{\Psi \Psi}$ & $68.1 \pm 3.76^{\Psi \Psi}$ \\
Group 4 & $30.1 \pm 1.66^{\Phi \Phi}$ & $78.8 \pm 4.35^{\Phi \Phi}$ & $73.2 \pm 4.04^{\Phi \Phi}$ \\
Group 5 & $26.3 \pm 1.45^{\Phi \Phi}$ & $70.6 \pm 3.90^{\Phi \Phi}$ & $74.5 \pm 4.67^{\Phi \Phi}$ \\
Group 6 & $22.5 \pm 1.24^{\Phi \Phi}$ & $67.3 \pm 3.72^{\Phi \Phi}$ & $89.1 \pm 4.92^{\Phi \Phi}$ \\
ANOVA & $28.5^{¥}$ & $40.6^{¥}$ & $11.12^{¥}$ \\
\hline
\end{tabular}

Data were expressed as mean \pm standard error of $n=6,{ }^{*}$ significant at $0.05 \%$ for ANOVA. ${ }^{\Psi \Psi}$ Beryllium against Control at $\mathrm{p} \leq 0.01$ and ${ }^{\Phi} \mathrm{Be}+$ Naringenin against Beryllium at $\leq 0.05,{ }^{\Phi \Phi} \mathrm{Be}+$ Naringenin against Beryllium at $\mathrm{p} \leq 0.01$ for Student's t-test. Group 1: Control, Group 2: Naringenin per se (Naringenin $50 \mathrm{mg} / \mathrm{kg}$ ), Group 3: Beryllium (1 mg/kg i.p. Once in a day; 4 weeks), Group 4: Beryllium+Naringenin $12.5 \mathrm{mg} / \mathrm{kg}$, Group 5: Beryllium+Naringenin $25 \mathrm{mg} / \mathrm{kg}$, Group 6: Beryllium+Naringenin $50 \mathrm{mg} / \mathrm{kg}$

\section{CONCLUSION}

The above study suggested that the oral administration of naringenin enable to minimize beryllium incited toxic manifestation in blood and serum markers. 25 and $50 \mathrm{mg} / \mathrm{kg}$ doses of naringenin were found to be more significant than the lowest dose, for diminishing beryllium harmful effects. It might be helpful in chelation of reactive free beryllium ions. Their structural affinity toward reactive free beryllium ion seized inside their lattice and kept as inactive form or assists to eliminate from the body of individual more easily. Hence, we could favor naringenin as a chelating agent against beryllium injury in the near future after an extensive investigation in it.

\section{AUTHORS' CONTRIBUTIONS}

All the authors have contributed equally to this investigation.

\section{CONFLICTS OF INTEREST}

The authors have declared that there are no conflicts of interest.

\section{ACKNOWLEDGMENT}

This work was partially financial supported by the University Grand Commission (UGC-MRP, F.42-520/2013SR). Department of Zoology and Department of Rural Technology and Social Development, Guru Ghasidas Vishwavidyalaya, Bilaspur are gratefully acknowledged for laboratory facilities. Guru Ghasidas Vishwavidyalaya for providing financial assistance in the form of University Fellowship.

\section{REFERENCES}

1. Sakr SA, Bayomy MF, El-Morsy AM. Rosemary extract ameliorates cadmium-induced histological changes and oxidative damage in the liver of albino rat. J Basic Appl Zool 2015;71:1-9.

2. Badeaa M, Luzardob OP, González-Antuña A, Zumbado M, Rogozea L, Floroian L, et al. Body burden of toxic metals and rare earth elements in non-smokers, cigarette smokers, and electronic cigarette users. Environ Res 2018;166:269-75.

3. Weston A, Snyder J, McCanlies EC, Schuler CR, Kreiss K, Demchuk E. Immunogenetic factors in beryllium sensitization and chronic beryllium disease. Mutat Res 2005;592:68-78.

4. Kolanz ME. Introduction to beryllium: Uses, regulatory history, and disease. Appl Occup Environ Hyg 2001;16:559-67.

5. Agency for Toxic Substances and Disease Registry. Toxicological Profile for Beryllium. Atlanta, Georgia: Agency for Toxic Substances and Disease Registry, US department of health and human services, Public Health Service; 2002.

6. World Health Organization. Environmental Health Criteria: 106 'Beryllium' International Programme on Chemical Safety. Geneva: World Health Organization; 1990.

7. Kamal AM, Abdelhady MS, Hadda TB. Two novel flavone c-glycosides isolated from Afrocarpus gracilior: Pom analyses and in vitro cytotoxic activity against hepatocellular carcinoma. Int J Pharm Pharm Sci 2019;11:57-62

8. Jain HK, Jaiswal SR. Effect of co-administration of Emblica officinalis and Aegle marmelos extracts for antioxidant and antidiabetic activity. Int J Pharm Pharm Sci 2019;11:81-9.

9. Pannu A, Goyal KR, Ojha S, Nandave M. Naringenin: A promising flavonoid for herbal treatment of rheumatoid arthritis and associated inflammatory disorder. In: Watson RR, Preedy VR, editors. Bioactive Food as Dietary Interventions for Arthritis and Related Inflammatory Diseases. $1^{\text {st }}$ ed. London: Academic Press; 2019.

10. Yoshida H, Watanabe H, Ishida A, Watanabe W, Narumic K, Atsumid T, et al. Naringenin suppresses macrophage infiltration into adipose tissue in an early phase of high-fat-diet-induced obesity. J Nutr Biochem 2014;454:95-101.

11. Bugianesi R, Catasta G, Spigno, P, D’Uva A, Maiani G. Naringenin from cooked tomato paste is bioavailable in men. J Nutr 2002;132:3349-52.

12. Pinho-Ribeiro FA, Zarpelon AC, Mizokami SS, Borghi SM, Bordignon J, Silva RL. The citrus flavanone naringenin reduces lipopolysaccharideinduced inflammatory pain and leukocyte recruitment by inhibiting NF$\kappa \mathrm{B}$ activation. J Nutr Biochem 2016;33:8-14.

13. Seyedrezazadeh E, Kolahian S, Shahbazfar AA, Ansarin K, Moghaddam MP, Sakhinia M, et al. Effects of the flavanone combination hesperetin-naringenin, and orange and grapefruit juices, on airway inflammation and remodeling in a murine asthma model. Phytother Res 2015;29:591-8.

14. Coelho RC, Hermsdorff HH, Bressan J. Anti-inflammatory properties of orange juice: Possible favorable molecular and metabolic effects. Plant Foods Hum Nutr 2013;68:1-10.

15. Dong D, Xu L, Yin L, Qi Y, Peng J. Naringenin prevents carbon tetrachloride-induced acute liver injury in mice. J Funct Foods 2015;12:179-91.

16. Yilma AN, Singh SR, Morici L, Dennis VA. Flavonoid naringenin: A potential immunomodulator for Chlamydia trachomatis inflammation. Mediators Inflamm 2013;2013:102457.

17. Varthan VJ, Srividya AR, Sathish KM. Role of naringin and naringenin in various diseased conditions a review. Int J Pharm Res 2013;2:1-4.

18. Yen HR, Liu CJ, Yeh CC. Naringenin suppresses TPA induced tumor invasion by suppressing multiple signal transduction pathways in human hepatocellular carcinoma cells. Chem Biol Interact 2015;235:1-9.

19. Ganapathy E, Peramaiyan R, Rajasekaran D, Venkataraman M, Dhanapal S. Modulatory effect of naringenin on N-methyl-N'nitro-N-nitrosoguanidine- and saturated sodium chloride-induced gastric carcinogenesis in male wistar rats. Exp Pharmacol Physiol 2008;35:1190-6.

20. Wang J, Yang Z, Lin L, Zhao Z, Liu Z, Liu X. Protective effect of naringenin against lead-induced oxidative stress in rats. Biol Trace Elem Res 2012; 146:354-3

21. Nirala SK, Bhadauria M, Mathur R, Mathur A. Influence of a-tocopherol, propolis and piperine on therapeutic potential of tiferron against beryllium-induced toxic manifestations. J Appl Toxicol 2008;28:44-54.

22. Nirala SK, Bhadauria M, Mathur R, Mathur A. Amelioration of beryllium alteration in hepatorenal biochemistry and ultramorphology by co-administration of tiferron and adjuvants. J Biomed Sci 2007; 14:331-45.

23. Snedecor GW, Cochran WG. Statistical Method. $8^{\text {th }}$ ed. Ames, Iowa: Iowa State University Press; 1994. p. 217.

24. Mershiba SD, Dassprakash MV, Saraswathy SD. Protective effect of naringenin on hepatic and renal dysfunction and oxidative stress in arsenic intoxicated rats. Mol Biol Rep 2013;40:3681-91.

25. Yanez JA, Remsberga CM, Mirandab ND, Vega-Villa KR, Andrews PK, NM Daviesa PK. Pharmacokinetics of selected chiral flavonoids: Hesperetin, naringenin, anderiodictyol in rats and their content in fruit juices. Biopharm Drug Dispos 2008;29:63-82.

26. Alam MA, Subhan N, Rahman MM, Uddin SJ, Reza HM, Sarker SD. Effect of citrus flavonoids, naringinand naringenin, on metabolic syndrome and their mechanisms of action. Adv Nutr 2008:5:404-17.

27. Zhao JQ, Du GZ, Xiong YC, Wen YF, Bhadauria M, Nirala SK. Attenuation of beryllium induced hepatorenal dysfunction and oxidative stress in rodents by combined effect of gallic acid and piperine. Arch Pharm Res 2007;30:1575-83

28. Hynes MJ, Coinceanainn MO. The kinetics and mechanisms of the reaction of iron (3) with gallic acid, gallic acid methyl ester, and catechin. J Inorg Biochem 2001;85:131-42.

29. Mathur S, Mathur R, Prakash AO. Protective action of Liv. 52: A herbal preparation against beryllium toxicity in rats. Biomed Environ Sci 1994;25:180-97.

30. Venugopal B, Luckey TD. Toxicity of group 2 metals. In: Metal 
Toxicity in Mammals. New York: Plenum Press; 1978. p. 43-58

31. Stockham, SL, Scott MA. Fundamentals of Veterinary Clinical Pathology, $2^{\text {nd }}$ ed. Ames, IA: Blackwell Publishing; 2008.

32. Sharon GB. Blood and bone marrow toxicity biomarkers. In: Gupta R, editors. Biomarkers in Toxicology. 2019.

33. Sahu N, Mishra G, Chandra HK, Nirala SK, Bhadauria M. Ameliorative effect of naringenin against antituberculosis drugs induced alterations in hematological parameters of rats. Asian $\mathrm{J}$ Pharm Clin Res
2018;11:253-5.

34. Renugadevi J, Prabu SM. Naringenin protects against cadmium-induced oxidative renal dysfunction in rats. Toxicol 2009;256:128-34.

35. Sahu N, Mishra G, Chandra HK, Nirala SK, Bhadauria M. Naringenin mitigates antituberculosis drugs induced hepatic and renal injury in rats. J Tradit Complement Med 2018; In Press.

36. Renugadevi J, Prabu SM. Cadmium-induced hepatotoxicity in rats and the protective effect of naringenin. Exp Toxicol Pathol 2010;62:171-81. 